\title{
A Novel Quadratic Boost Converter With Low Inductor Currents
}

\author{
Guanlin Li, Xin Jin, Xiyou Chen, and Xianmin Mu
}

\begin{abstract}
In this paper, a novel quadratic boost converter is presented. The input current of the converter is non-pulsating and the currents of the inductors are relatively low. The operating principle and the mathematical model of the converter in continuous conduction mode (CCM) are given. The steady-state of the converter is calculated and the power loss of the converter is analyzed. Then the small-signal model of the converter is derived based on the state space averaging method. The inductor current and the voltage stress of the proposed converter arelow, which can improve the efficiency of the converter. The simulations and the circuit experiments are presented to verify the good performance of the converter.
\end{abstract}

Index Terms-Inductor current, quadratic boost converter, steady state.

\section{INTRODUCTION}

$\mathrm{R}$ ECENT years, more attention has been paid to the renewable energy for the increasing cost of fossil fuel and the regulations of $\mathrm{CO}_{2}$ emissions [1]. The output voltage of these energy sources, such as solar panel and fuel cells, is low and variable. Thus, it needs high-ratio DC-DC converter to get the appropriate output voltage [2]. In order to obtain a high output voltage, the conventional boost converter must operate at extremely high duty-cycle ratios, that is quite difficult to be obtained in practical application for the limitation of semiconductors. Small off times cause high switching voltage stress with reverse recovery issues and the low efficiency [3].

A number of high step-up converter topologies have been proposed to get the high voltage gain with suitable duty cycle. Converters with coupled inductors can achieve a high step up voltage gain [4], but their efficiency is low for the losses of leakage inductors. The active-clamp circuit has been applied and can recycle the leakage energy [5], [6]. Also, the switched capacitor is a well-known voltage boosting technique based a charge pump circuit used in many converters [2], [7]. Another method for increasing voltage gain of a DC-DC converter is to employ several stages of converter modules in some ways, such as the quadratic boost converter [8].

Manuscript received July 15, 2019; revised September 12, 2019 and December 27, 2019; accepted March 1, 2020. Date of publication March 31, 2020; date of current version February 28, 2020. This work was supported by the National Nature Science Foundation of China under Grant 51307013.

All authors are with the Department of Electrical Engineering, Dalian University of Technology, Dalian, China (e-mail: lglhit@dlut.edu.cn).

Digital Object Identifier 10.24295/CPSSTPEA.2020.00001
The voltage gain of the quadratic converter is the quadratic function of its duty ratio [9]. A quadratic cascade boost converter is proposed by F. L. Luo in [10]. A multistage cascade quadratic converter with several voltage-boosting modules and only one active switch is presented in [11]. In [12], a quadratic boost converter with low capacitor voltage stress is proposed. However, the input current of this converter is pulsating, thus it is necessary and difficult to design input filter. Another quadratic boost converter with two active switches is proposed by [13], where the active switches are controlled by the same PWM signal. The input current of the converter in [13] is continuous, and the voltage stress on power switch is low. In [14], a novel quadratic boost converter with low inductor currents is proposed. Its voltage gain is the same as the conventional quadratic boost converter. The input current of the proposed converter is non-pulsating, the voltage stress on power switch is low, and the inductors' current of the proposed converter is low, that can decrease the power losses and increase the efficiency of the converter.

In this paper, the novel quadratic boost converter in [14] is analyzed in detail, and the circuit experiments are presented to verify the good performance of the proposed converter. This paper is organized as follows. In Section II, the topology and operating principle in CCM are given. The steady state analysis and the loss analysis are presented in Sections III and $\mathrm{V}$, respectively. The comparisons among the proposed converter and the other quadratic boost converters in [10], [12] and [13] are given in Sections IV. The small-signal model is described in Section VI. In Sections VII and VIII, the simulations and the circuit experiments are presented for verification. Some conclusions and future work are concluded in Section IX.

\section{Operating Principle of the Proposed Converter}

The proposed converter is shown in Fig. 1(a). This converter consists of two power switches $\mathrm{S}_{1}$ and $\mathrm{S}_{2}$, two diodes $\mathrm{D}_{1}$ and $\mathrm{D}_{2}$, two inductors $L_{1}$ and $L_{2}$, two capacitors $C_{1}$ and $C_{2}$, and the load $R_{\mathrm{L}}$. Two power switches are controlled synchronously and driven by the same PWM signal with the period being $T$ and the duty cycle being $D$.

The proposed converter working in CCM contains two modes. In the first mode, $t \in(N T, N T+D T)$ the power switch $\mathrm{S}_{1}$ and $\mathrm{S}_{2}$ are turned on and the diodes $\mathrm{D}_{1}$ and $\mathrm{D}_{2}$ are not conducted for the inverse biased voltage, as shown in Fig. 1(b). The second mode $t \in(N T+D T, N T+T)$ is shown in Fig. 1(c). The power switches $\mathrm{S}_{1}$ and $\mathrm{S}_{2}$ are turned off in this mode. The diodes are conducted for its forward biased voltage. The related equations of the two modes can be written as follows: 


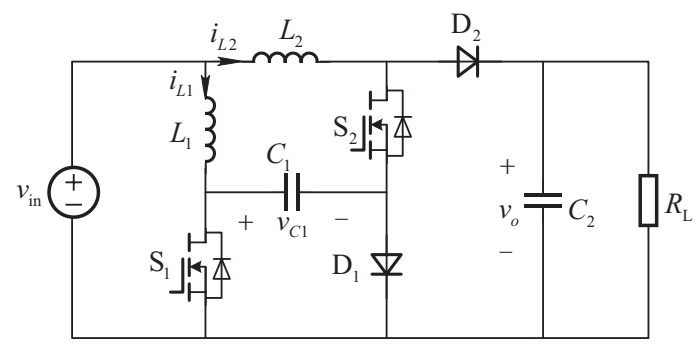

(a)

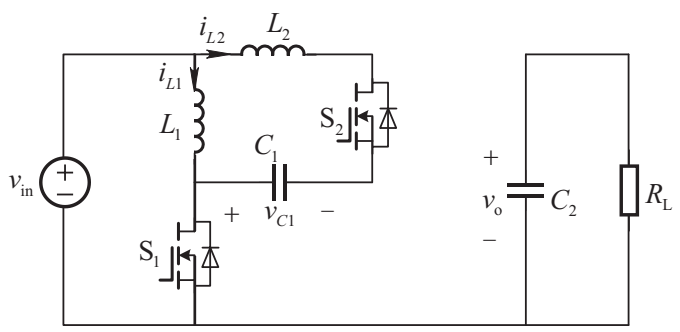

(b)

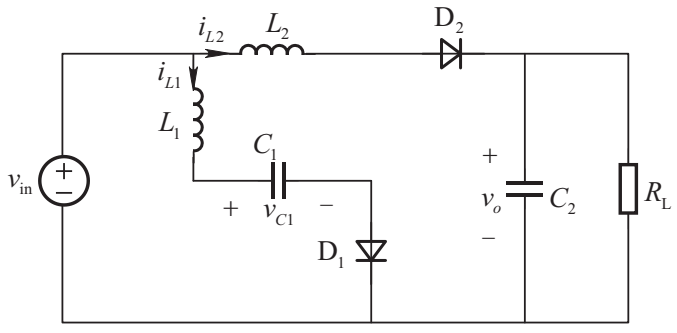

(c)

Fig. 1. (a) Proposed quadratic boost converter. (b) Mode 1. (c) Mode 2.

$$
\begin{aligned}
& L_{1} \frac{\mathrm{d} i_{L 1}}{\mathrm{~d} t}=v_{\text {in }} \\
& L_{2} \frac{\mathrm{d} i_{L 2}}{\mathrm{~d} t}=v_{C 1}+v_{\text {in }} \\
& \left\{C_{1} \frac{\mathrm{d} v_{C 1}}{\mathrm{~d} t}=-i_{L 2} \quad t \in(N T, N T+D T)\right. \\
& C_{2} \frac{\mathrm{d} v_{\mathrm{o}}}{\mathrm{d} t}=-\frac{v_{\mathrm{o}}}{R_{\mathrm{L}}} \\
& L_{1} \frac{\mathrm{d} i_{L 1}}{\mathrm{~d} t}=v_{\mathrm{in}}-v_{C 1} \\
& L_{2} \frac{\mathrm{d} i_{L 2}}{\mathrm{~d} t}=v_{\text {in }}-v_{\text {o }} \\
& C_{1} \frac{\mathrm{d} v_{C 1}}{\mathrm{~d} t}=i_{L 1} \\
& C_{2} \frac{\mathrm{d} v_{\mathrm{o}}}{\mathrm{d} t}=i_{L 2}-\frac{v_{\mathrm{o}}}{R_{\mathrm{L}}}
\end{aligned}
$$

\section{Steady State Analysis}

For steady-state theoretical analysis, it is assumed that all components are ideal and the proposed converter operates in CCM. It is assumed that $V_{\text {in }}, V_{C 1}, I_{L 1}, I_{L 2}, I_{\mathrm{o}}$ and $V_{\mathrm{o}}$ are corresponding DC values of $v_{\text {in }}, v_{C 1}, i_{L 1}, i_{L 2}, i_{\mathrm{o}}$ and $v_{\mathrm{o}}$.
TABLE I

DC VALUES OF THE Proposed CONVERTER

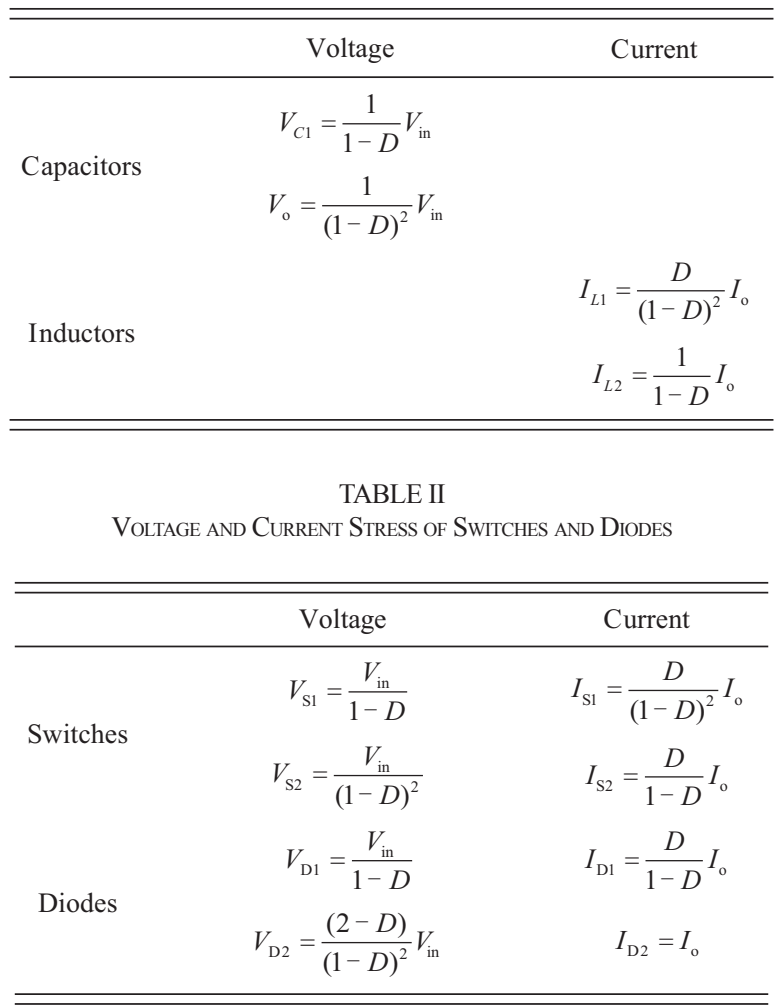

The DC values of the converter can be deduced as Table I by applying voltage-second balance and charge balance principle. Thus, the voltage conversion ratio of the proposed converter can be derived as (3).

$$
M=\frac{V_{\mathrm{o}}}{V_{\mathrm{in}}}=\frac{1}{(1-D)^{2}}
$$

From Fig. 1 and Table I, the voltage stress and current stress of the switches and diodes can be derived as Table II. These parameters are useful for selecting the specific model of the devices in subsequent experiments.

Some of the waveforms of the proposed converter in CCM mode are shown in Fig. 2.

From the time-domain waveforms shown in Fig. 2, the peakto-peak ripple can be deduced as follows:

$$
\begin{aligned}
& \Delta i_{L 1}=\frac{D T V_{\mathrm{in}}}{L_{1}} ; \Delta i_{L 2}=\frac{D(2-D) T V_{\mathrm{in}}}{(1-D) L_{2}} ; \\
& \Delta v_{C 1}=\frac{D T V_{\mathrm{o}}}{(1-D) R_{\mathrm{L}} C_{1}} ; \Delta v_{\mathrm{o}}=\frac{D T V_{\mathrm{o}}}{R_{\mathrm{L}} C_{2}} .
\end{aligned}
$$

Current ripple ratios $\left(\rho_{L 1}=\Delta i_{L 1} / I_{L 1}\right.$ and $\left.\rho_{L 2}=\Delta i_{L 2} / I_{L 2}\right)$ and voltage ripple ratios $\left(\rho_{C 1}=\Delta v_{C 1} / V_{C 1}\right.$ and $\left.\rho_{\mathrm{o}}=\Delta v_{\mathrm{o}} / V_{\mathrm{o}}\right)$ which are useful for selecting the values of inductors and capacitors are calculated.

$$
\begin{aligned}
& \rho_{L 1}=\frac{R_{\mathrm{L}} T(1-D)^{4}}{L_{1}} ; \rho_{L 2}=\frac{(1-D)^{2}(2-D) D R_{\mathrm{L}} T}{L_{2}} ; \\
& \rho_{C 1}=\frac{D T}{(1-D)^{2} R_{\mathrm{L}} C_{1}} ; \rho_{\mathrm{o}}=\frac{\Delta v_{\mathrm{o}}}{V_{\mathrm{o}}}=\frac{D T}{R_{\mathrm{L}} C_{2}} .
\end{aligned}
$$




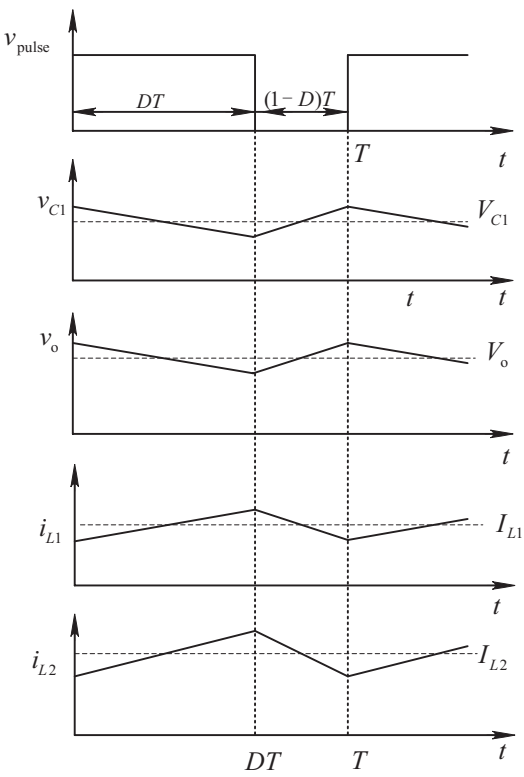

Fig. 2. Some typical waveforms of the proposed converter.

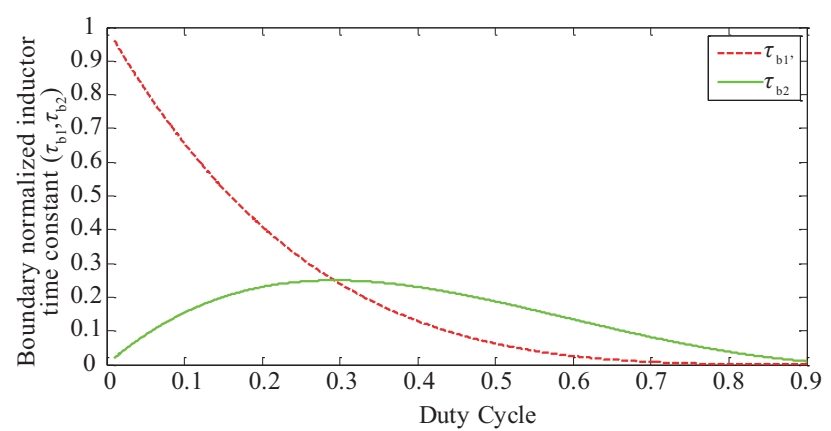

Fig. 3. Curves of boundary inductory time constants $\tau_{\mathrm{b} 1}$ and $\tau_{\mathrm{b} 2}$.

The boundary between continuous conduction mode and discontinuous conduction mode is that the inductor current decrease to zero, that is $I_{L 1}=\Delta i_{L 1} / 2$ and $I_{L 2}=\Delta i_{L 2} / 2$. The condition for the proposed converter working in continuous conduction mode can be derived as follows:

$$
\begin{aligned}
& \tau_{L 1}=\frac{2 L_{1}}{R_{\mathrm{L}} T} \geqslant \tau_{\mathrm{b} 1}=(1-D)^{4} \\
& \tau_{L 2}=\frac{2 L_{2}}{R_{\mathrm{L}} T} \geqslant \tau_{\mathrm{b} 2}=D(1-D)^{2}(2-D) .
\end{aligned}
$$

$\tau_{\mathrm{b} 1}$ and $\tau_{\mathrm{b} 2}$ are normalized inductor time constants. The curves for $\tau_{\mathrm{b} 1}$ and $\tau_{\mathrm{b} 2}$ are shown in Fig. 3. From the proposed converter in the operating point, if $\tau_{L 1} \geqslant \tau_{\mathrm{b} 1}$ and $\tau_{L 2} \geqslant \tau_{\mathrm{b} 2}$, the converter will work in CCM. Otherwise, the converter will operate in DCM.

\section{Comparisons of Quadratic Boost Converters}

There are some quadratic boost converters in the literatures. The quadratic cascade boost converter is proposed by F. L. Luo

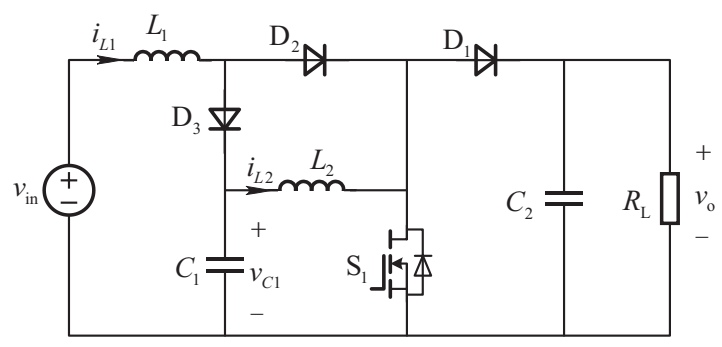

(a)

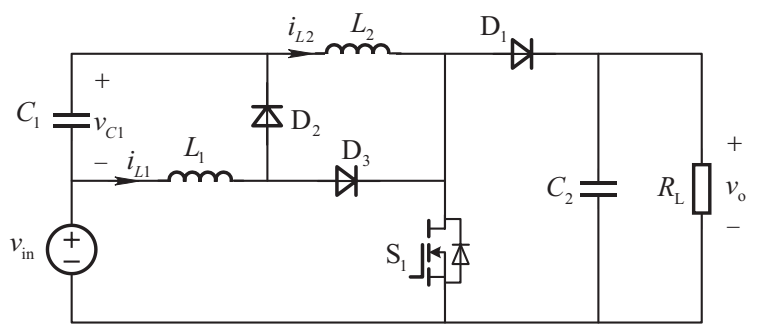

(b)

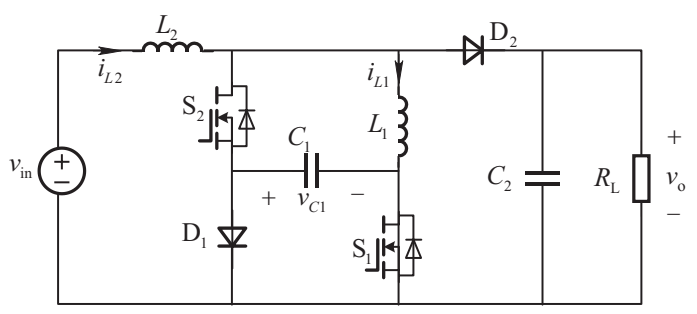

(c)

Fig. 4. Some existing quadratic boost converter. (a) Converter in [10]. (b) Converter in [12]. (c) Converter in [13].

in [10]. Then, a quadratic boost converter with low capacitor voltage stress is proposed by Y. M. Ye in [12]. F. Wang proposed another quadratic boost converter with two active switches in [13]. The respective circuit diagrams are shown in Fig. 4(a), (b) and (c).

The inductor currents, the inductor ripple currents, the currents flowing through the switches and the diodes, the output voltage, the voltage stress and the input current of the proposed converter (PCV) are compared with those terms in [10], [12] and [13], which are shown in Table III.

From Table III, we can conclude that under the same conditions, the average current of the first inductor of the proposed converter $\left(I_{L 1}\right)$ is lower than that in [10], [12], and the second average inductor current of the PCV $\left(I_{L 2}\right)$ is lower than that in [13], which can reduce the copper loss of the inductors and increase the efficiency of the converter. Moreover, the ripple current of the first inductor of the $\operatorname{PCV}\left(\Delta i_{L 1}\right)$ is also lower than [13]. The average currents flowing through the switches of the PCV are same as that in [13], but average current flowing through $S_{1}$ is smaller than that in [10], [12]. The voltage stress of the proposed converter is same as that in [13], but voltage stress on $S_{1}$ is smaller than that in [10], [12]. The input current of PCV is non-pulsating since its value is equal to $i_{L 1}$ plus $i_{L 2}$, that will make the design of the input filter much easier. 
TABLE III

COMParisons Among DifFerent CONVERTERS

\begin{tabular}{|c|c|c|c|c|c|}
\hline & & $C[10]$ & $\mathrm{C}[12]$ & $\mathrm{C}[13]$ & $\mathrm{PCV}$ \\
\hline \multirow{4}{*}{$I_{L}$} & $I_{L 1}$ & $\frac{I_{\mathrm{o}}}{(1-D)^{2}}$ & $\frac{I_{\mathrm{o}}}{(1-D)^{2}}$ & $\frac{D I_{o}}{(1-D)^{2}}$ & $\frac{D I_{\mathrm{o}}}{(1-D)^{2}}$ \\
\hline & $I_{L 2}$ & $\frac{I_{\mathrm{o}}}{1-D}$ & $\frac{I_{\mathrm{o}}}{1-D}$ & $\frac{I_{\mathrm{o}}}{(1-D)^{2}}$ & $\frac{I_{0}}{1-D}$ \\
\hline & $\Delta i_{L 1}$ & $\frac{D T V_{\text {in }}}{L_{1}}$ & $\frac{D T V_{\text {in }}}{L_{1}}$ & $\frac{D T V_{\text {in }}}{(1-D) L_{1}}$ & $\frac{D T V_{\text {in }}}{L_{1}}$ \\
\hline & $\Delta i_{L 2}$ & $\frac{D T V_{\text {in }}}{(1-D) L_{2}}$ & $\frac{D T V_{\mathrm{in}}}{(1-D) L_{2}}$ & $\frac{D(2-D) T V_{\text {in }}}{(1-D) L_{2}}$ & $\frac{D(2-D) T V_{\mathrm{in}}}{(1-D) L_{2}}$ \\
\hline \multirow{2}{*}{$I_{\mathrm{S}}$} & $\mathrm{S}_{1}$ & $\frac{(2-D) D I_{\mathrm{o}}}{(1-D)^{2}}$ & $\frac{(2-D) D I_{0}}{(1-D)^{2}}$ & $\frac{D I_{\mathrm{o}}}{(1-D)^{2}}$ & $\frac{D I_{\mathrm{o}}}{(1-D)^{2}}$ \\
\hline & $\mathrm{S}_{2}$ & & & $\frac{D I_{\mathrm{o}}}{(1-D)}$ & $\frac{D I_{\mathrm{o}}}{1-D}$ \\
\hline \multirow{3}{*}{$I_{\mathrm{D}}$} & $\mathrm{D}_{1}$ & $I_{\mathrm{o}}$ & $I_{\mathrm{o}}$ & $\frac{D}{1-D} I_{\mathrm{o}}$ & $\frac{D}{1-D} I_{\mathrm{o}}$ \\
\hline & $\mathrm{D}_{2}$ & $\frac{D I_{\mathrm{o}}}{(1-D)^{2}}$ & $\frac{I_{\mathrm{o}}}{1-D}$ & $I_{\mathrm{o}}$ & $I_{\mathrm{o}}$ \\
\hline & $\mathrm{D}_{3}$ & $\frac{I_{o}}{1-D}$ & $\frac{D I_{\mathrm{o}}}{(1-D)^{2}}$ & & \\
\hline \multirow{2}{*}{$V_{\mathrm{S}}$} & $\mathrm{S}_{1}$ & $\frac{V_{\text {in }}}{(1-D)^{2}}$ & $\frac{V_{\text {in }}}{(1-D)^{2}}$ & $\frac{V_{\mathrm{in}}}{1-D}$ & $\frac{V_{\mathrm{in}}}{1-D}$ \\
\hline & $\mathrm{S}_{2}$ & & & $\frac{V_{\text {in }}}{(1-D)^{2}}$ & $\frac{V_{\text {in }}}{(1-D)^{2}}$ \\
\hline \multirow{3}{*}{$V_{\mathrm{D}}$} & $\mathrm{D}_{1}$ & $\frac{V_{\text {in }}}{(1-D)^{2}}$ & $\frac{V_{\text {in }}}{(1-D)^{2}}$ & $\frac{V_{\text {in }}}{1-D}$ & $\frac{V_{\text {in }}}{1-D}$ \\
\hline & $\mathrm{D}_{2}$ & $\frac{D V_{\text {in }}}{(1-D)^{2}}$ & $\frac{V_{\mathrm{in}}}{1-D}$ & $\frac{(2-D) V_{\text {in }}}{(1-D)^{2}}$ & $\frac{(2-D) V_{\text {in }}}{(1-D)^{2}}$ \\
\hline & $\mathrm{D}_{3}$ & $\frac{V_{\mathrm{in}}}{1-D}$ & $\frac{D V_{\text {in }}}{(1-D)^{2}}$ & & \\
\hline \multicolumn{2}{|c|}{$V_{\mathrm{o}}$} & $\frac{V_{\text {in }}}{(1-D)^{2}}$ & $\frac{V_{\text {in }}}{(1-D)^{2}}$ & $\frac{V_{\text {in }}}{(1-D)^{2}}$ & $\frac{V_{\text {in }}}{(1-D)^{2}}$ \\
\hline \multicolumn{2}{|c|}{$\begin{array}{l}\text { Input } \\
\text { current }\end{array}$} & $\begin{array}{c}\text { Non- } \\
\text { pulsating }\end{array}$ & Pulsating & $\begin{array}{c}\text { Non- } \\
\text { pulsating }\end{array}$ & $\begin{array}{c}\text { Non- } \\
\text { pulsating }\end{array}$ \\
\hline
\end{tabular}

\section{ANLysis of the Power Loss}

Power loss of the proposed converter is analyzed in this part. The total power losses of the converter include the losses of power switches, diodes, inductors and capacitors. The parasitic resistances are defined as follows: $r_{\mathrm{ds} 1}$ and $r_{\mathrm{ds} 2}$ are the switch onstate resistances; $r_{\mathrm{F} 1}$ and $r_{\mathrm{F} 2}$ are the forward resistances of diodes $\mathrm{D}_{1}$ and $\mathrm{D}_{2} ; r_{L 1}$ and $r_{L 2}$ are the equivalent series resistance (ESR) of inductors $L_{1}$ and $L_{2} ; r_{C 1}$ and $r_{C 2}$ are the ESR of capacitors $C_{1}$ and $C_{2}$; forward voltages $V_{\mathrm{F} 1}$ and $V_{\mathrm{F} 2}$ are the forward bias voltages of diodes $\mathrm{D}_{1}$ and $\mathrm{D}_{2}$. The voltage ripple across the capacitors and the inductors is ignored.

\section{A. Power Losses of Power Switches}

MOSFET is chosen as the power switch of the proposed converter. The losses of the power switches include the conduction loss and the switching loss. The conduction power losses of the switches can be calculated as follows:

$$
\begin{aligned}
P_{\mathrm{SWC}} & =r_{\mathrm{ds} 1} I_{\mathrm{S} 1, \mathrm{rms}}^{2}+r_{\mathrm{ds} 2} I_{\mathrm{S} 2, \mathrm{rms}}^{2}=r_{\mathrm{ds} 1} D\left(I_{L 1}+I_{L 2}\right)^{2}+r_{\mathrm{ds} 2} D I_{L 2}^{2} \\
& =\frac{r_{\mathrm{ds} 1} D}{(1-D)^{4}} \frac{V_{\mathrm{o}}^{2}}{R_{\mathrm{L}}^{2}}+\frac{r_{\mathrm{ds} 2} D}{(1-D)^{2}} \frac{V_{\mathrm{o}}^{2}}{R_{\mathrm{L}}^{2}}
\end{aligned}
$$

The switching losses are related to the rise time $t_{\mathrm{r}}$ and the fall time $t_{\mathrm{f}}$ of the switch $\left(t_{\mathrm{off}}=t_{\mathrm{r}}+t_{\mathrm{f}}\right)$, the voltage across the power switch $V_{\mathrm{S}}$ and the averaged current $I_{\mathrm{S}}$ across it.

$$
\begin{aligned}
P_{\mathrm{SW} \text { off }} & =\frac{1}{2} I_{\mathrm{S} 1} V_{\mathrm{S} 1} t_{\mathrm{off} 1} f_{\mathrm{s}}+\frac{1}{2} I_{\mathrm{S} 2} V_{\mathrm{S} 2} t_{\mathrm{off} 2} f_{\mathrm{s}} \\
& =\frac{1}{2} \frac{D V_{\mathrm{o}}^{2}}{(1-D) R_{\mathrm{L}}} t_{\mathrm{off} 1} f_{\mathrm{s}}+\frac{1}{2} \frac{D V_{\mathrm{o}}^{2}}{(1-D) R_{\mathrm{L}}} t_{\mathrm{off} 2} f_{\mathrm{s}}
\end{aligned}
$$

where $f_{\mathrm{s}}$ is the switching frequency, $f_{\mathrm{s}}=1 / T ; t_{\mathrm{offl}}$ and $t_{\mathrm{off2}}$ are the turn off across time of the switches $\mathrm{S}_{1}$ and $\mathrm{S}_{2}$, respectively.

The total losses of the switch $\mathrm{S}\left(P_{\text {Switch,tot }}\right)$ can be earned as follows:

$$
P_{\text {Switch,tot }}=P_{\mathrm{SWC}}+P_{\mathrm{SW} \text { off }}
$$

\section{B. Power Losses of Diodes}

The power loss of diode is mainly caused by the forward voltage drop $V_{\mathrm{F} 1}$ and $V_{\mathrm{F} 2}$, and the series resistance $r_{\mathrm{F} 1}$ and $r_{\mathrm{F} 2}$.

The diodes $\mathrm{D}_{1}$ and $\mathrm{D}_{2}$ forward resistance losses can be get as follows:

$$
P_{\mathrm{RFD}}=r_{\mathrm{F} 1} I_{\mathrm{D} 1, \mathrm{rms}}^{2}+r_{\mathrm{F} 2} I_{\mathrm{D} 2, \mathrm{rms}}^{2}=\frac{r_{\mathrm{F} 1} D^{2} V_{\mathrm{o}}^{2}}{(1-D)^{3} R_{\mathrm{L}}^{2}}+\frac{r_{\mathrm{F} 2} V_{\mathrm{o}}^{2}}{(1-D) R_{\mathrm{L}}^{2}}
$$

The diodes $\mathrm{D}_{1}$ and $\mathrm{D}_{2}$ forward voltage losses can be achieved as follows:

$$
P_{\mathrm{VFD}}=V_{\mathrm{F} 1} I_{\mathrm{D} 1}+V_{\mathrm{F} 2} I_{\mathrm{D} 2}=V_{\mathrm{F} 1} \frac{D V_{\mathrm{o}}}{(1-D) R_{\mathrm{L}}}+V_{\mathrm{F} 2} \frac{V_{\mathrm{o}}}{R_{\mathrm{L}}}
$$

The total losses of the diodes $\mathrm{D}_{1}$ and $\mathrm{D}_{2}\left(P_{\mathrm{D}}\right)$ can be deduced as follows:

$$
P_{\mathrm{D}}=P_{\mathrm{RFD}}+P_{\mathrm{VFD}}
$$

\section{Power Losses of Inductors}

The power loss of inductor has copper loss caused by winding resistance $\left(r_{L 1}\right.$ and $\left.r_{L 2}\right)$ and core loss caused by hysteresis and eddy current in the magnetic core.

The copper loss places an important role in the total power loss of inductor. The conduction losses of the inductors $L_{1}$ and $L_{2}$ can be get as follows:

$$
P_{L r}=r_{L 1} I_{L 1, \mathrm{rms}}^{2}+r_{L 2} I_{L 2, \mathrm{rms}}^{2}=\frac{r_{L 1} D^{2} V_{\mathrm{o}}^{2}}{(1-D)^{4} R_{\mathrm{L}}^{2}}+\frac{r_{L 2} V_{\mathrm{o}}^{2}}{(1-D)^{2} R_{\mathrm{L}}^{2}}
$$


Obviously, decreasing the RMS of the currents flowing through $L_{1}$ and $L_{2}$ can reduce the copper losses of the inductors.

The iron losses $P_{L \mathrm{fe}}$ of the inductors $L_{1}$ and $L_{2}$ mainly consist of two parts: the magnetic hysteresis loss $\left(P_{L \mathrm{~h}}, P_{L \mathrm{Lh}}\right)$ and the eddy current loss $\left(P_{L \mathrm{c} 1}, P_{\mathrm{Lc} 2}\right)$.

$$
\begin{aligned}
P_{L \mathrm{Le}} & =P_{\mathrm{Lh} 1}+P_{L \mathrm{c} 1}+P_{L \mathrm{~h} 2}+P_{L \mathrm{c} 2} \\
& =K_{\mathrm{h} 1} f B_{\mathrm{m} 1}^{2}+K_{\mathrm{c} 1}\left(f B_{\mathrm{m} 1}\right)^{2}+K_{\mathrm{h} 2} f B_{\mathrm{m} 2}^{2}+K_{\mathrm{c} 2}\left(f B_{\mathrm{m} 2}\right)^{2}
\end{aligned}
$$

where $K_{\mathrm{h} 1}$ and $K_{\mathrm{h} 2}$ are the loss coefficients related to the hysteresis loss, $K_{\mathrm{cl}}$ and $K_{\mathrm{c} 2}$ are the loss coefficients related to the eddy current loss, $f$ is the frequency of the voltages across the inductors, $B_{\mathrm{m} 1}$ and $B_{\mathrm{m} 2}$ are the magnetic flux density, which is related to the current flowing through the inductors $L_{1}$ and $L_{2}$, respectively.

$$
B_{\mathrm{m} 1}=\mu H_{1}=\mu k_{1} I_{L 1}, B_{\mathrm{m} 2}=\mu H_{2}=\mu k_{2} I_{L 2},
$$

where $\mu$ is the magnetic permeability of the iron core, $H_{1}$ and $H_{2}$ are the magnetic field intensity, $k_{1}$ and $k_{2}$ are the constant coefficients. Thus, the iron losses $P_{L \mathrm{fe}}$ of the inductors $L_{1}$ and $L_{2}$ can be deduced as follows:

$$
\begin{aligned}
P_{L \mathrm{Le}} & =P_{L \mathrm{~h} 1}+P_{L \mathrm{Lc} 1}+P_{L \mathrm{~h} 2}+P_{L \mathrm{c} 2} \\
& =\frac{\left(K_{\mathrm{h} 1} f+K_{\mathrm{cc}} f^{2}\right) k_{1}^{2} \mu^{2} D^{2} V_{\mathrm{o}}^{2}}{(1-D)^{4} R_{\mathrm{L}}^{2}}+\frac{\left(K_{\mathrm{h} 2} f+K_{\mathrm{c} 2} f^{2}\right) k_{2}^{2} \mu^{2} V_{\mathrm{o}}^{2}}{(1-D)^{2} R_{\mathrm{L}}^{2}}
\end{aligned}
$$

Due to the magnetic saturation, $\mu$ decreases as the current flowing through the inductor increases. The iron losses $P_{L \mathrm{fe}}$ of the given inductors with certain frequency can be considered as a fixed value when the load $R_{\mathrm{L}}$ varies.

The total power losses of inductors are the sum of core loss and copper loss, that is,

$$
P_{L}=P_{L \mathrm{fe}}+P_{L r}
$$

\section{Power Losses of Capacitors}

The power losses of capacitors $C_{1}$ and $C_{2}$ due to the ESR can be obtained as follows:

$$
P_{C}=r_{C 1} I_{C 1, \mathrm{mms}}^{2}+r_{C 2} I_{C 2, \mathrm{~ms}}^{2}=\frac{r_{C 1} D V_{\mathrm{o}}^{2}}{(1-D)^{3} R_{\mathrm{L}}^{2}}+\frac{r_{C 2} D V_{\mathrm{o}}^{2}}{(1-D) R_{\mathrm{L}}^{2}}
$$

\section{E. Efficiency}

The total power dissipation of the proposed converter is the sum of the power losses of power switches, diodes, inductors and capacitors, that is,

$$
P_{\text {Loss }}=P_{\text {Switch,tot }}+P_{\mathrm{D}}+P_{L}+P_{C}
$$

Thus, the efficiency $\eta$ of the converter can be obtained as follows:

$$
\eta=\frac{P_{\mathrm{o}}}{P_{\mathrm{o}}+P_{\mathrm{Loss}}}=\frac{1}{1+\frac{P_{\mathrm{Loss}} R_{\mathrm{L}}}{V_{\mathrm{o}}^{2}}} .
$$

\section{Small-Signal Modeling}

Based on state averaging method, the average model of the proposed converter operating in CCM mode can be described as follows:

$$
\left\{\begin{array}{l}
L_{1} \frac{\mathrm{d}<i_{L 1}>}{\mathrm{d} t}=\left\langle v_{\mathrm{in}}>-(1-d)<v_{C 1}>\right. \\
L_{1} \frac{\mathrm{d}<i_{L 2}>}{\mathrm{d} t}=\left\langle v_{\mathrm{in}}>+d<v_{C 1}>-(1-d)<v_{\mathrm{o}}>\right. \\
C_{1} \frac{\mathrm{d}<v_{C 1}>}{\mathrm{d} t}=-d<i_{L 2}>+(1-d)<i_{L 1}> \\
C_{2} \frac{\mathrm{d}<v_{\mathrm{o}}>}{\mathrm{d} t}=(1-d)<i_{L 2}>-\frac{<v_{\mathrm{o}}>}{R_{\mathrm{L}}}
\end{array}\right.
$$

where $\left\langle i_{L 1}>,\left\langle i_{L 2}\right\rangle,\left\langle v_{\text {in }}>,\left\langle v_{C 1}\right\rangle\right.\right.$ and $\left\langle v_{0}>\right.$ are the average values of $i_{L 1}, i_{L 2}, v_{\mathrm{in}}, v_{C 1}$ and $v_{\mathrm{o}}$ respectively. $d$ is the duty cycle.

The small ac perturbations are given as follows:

$$
\left\{\begin{array}{l}
<i_{L 1}>=I_{L 1}+\hat{i}_{L 1} \\
<i_{L 2}>=I_{L 2}+\hat{i}_{L 2} \\
<v_{C 1}>=V_{C 1}+\hat{v}_{C 1} \\
<v_{0}>=V_{o}+\hat{v}_{\mathrm{o}} \\
<v_{\text {in }}>=V_{\text {in }}+\hat{v}_{\text {in }} \\
<d>=D+\hat{d}
\end{array}\right.
$$

where, the small ac signals and the DC values satisfy the following conditions, that is,

$$
\left\{\begin{array}{l}
\hat{i}_{L 1} \ll I_{L 1} \\
\hat{i}_{L 2} \ll I_{L 2} \\
\hat{v}_{C 1} \ll V_{C 1} \\
\hat{v}_{\mathrm{o}} \ll V_{\mathrm{o}} \\
\hat{v}_{\text {in }} \ll V_{\text {in }} \\
\hat{d} \ll D
\end{array} .\right.
$$

Substituting (20) and (21) into (19), separating the smallsignal ac terms from (19), omitting the higher-order small signal terms, and the small ac equations of the proposed converter can be obtained as follows: 


$$
\left\{\begin{array}{l}
L_{1} \frac{\mathrm{d} \hat{i}_{L 1}}{\mathrm{~d} t}=\hat{v}_{\mathrm{in}}+V_{C 1} \hat{d}-(1-D) \hat{v}_{C 1} \\
L_{2} \frac{\mathrm{d} \hat{i}_{L 2}}{\mathrm{~d} t}=\hat{v}_{\mathrm{in}}+\left(V_{C 1}+V_{\mathrm{o}}\right) \hat{d}+D \hat{v}_{C 1}-(1-D) \hat{v}_{\mathrm{o}} \\
C_{1} \frac{\mathrm{d} \hat{v}_{C 1}}{\mathrm{~d} t}=-\left(I_{L 1}+I_{L 2}\right) \hat{d}+(1-D) \hat{i}_{L 1}-D \hat{i}_{L 2} \\
C_{2} \frac{\mathrm{d} \hat{v}_{\mathrm{o}}}{\mathrm{d} t}=-I_{L 2} \hat{d}+(1-D) \hat{i}_{L 2}-\frac{\hat{v}_{\mathrm{o}}}{R_{\mathrm{L}}}
\end{array}\right.
$$

Using Laplace transform, the transfer functions of the output voltage to the duty cycle $G_{v d}(s)$ and the first inductor current to the duty cycle $G_{i l d}(s)$ can be deduced as follows:

$$
\begin{aligned}
G_{v d}(s) & =\left.\frac{\hat{v}_{0}(s)}{\hat{d}(s)}\right|_{\hat{v}_{\text {in }}(s)=0} \\
& =\frac{b_{3} s^{3}+b_{2} s^{2}+b_{1} s+b_{0}}{(1-D)^{3}\left(a_{4} s^{4}+a_{3} s^{3}+a_{2} s^{2}+a_{1} s+a_{0}\right)} \\
G_{i l d}(s) & =\left.\frac{\hat{i}_{L 1}(s)}{\hat{d}(s)}\right|_{\hat{v}_{\text {in }}(s)=0} \\
& =\frac{m_{3} s^{3}+m_{2} s^{2}+m_{1} s+m_{0}}{(1-D)^{3}\left(a_{4} s^{4}+a_{3} s^{3}+a_{2} s^{2}+a_{1} s+a_{0}\right)}
\end{aligned}
$$

where,

$$
\left\{\begin{array}{l}
a_{4}=R_{\mathrm{L}} L_{1} L_{2} C_{1} C_{2} \\
a_{3}=L_{1} L_{2} C_{1} \\
a_{2}=(1-D)^{2} R_{\mathrm{L}} L_{1} C_{1}+(1-D)^{2} R_{\mathrm{L}} L_{2} C_{2}+D^{2} R_{\mathrm{L}} L_{1} C_{2} \\
a_{1}=(1-D)^{2} L_{2}+D^{2} L_{1} \\
a_{0}=R_{\mathrm{L}}(1-D)^{4} \\
b_{3}=-V_{\text {in }} L_{1} L_{2} C_{1} \\
b_{2}=(1-D)^{2}(2-D) V_{\text {in }} R_{\mathrm{L}} L_{1} C_{1} \\
b_{1}=-V_{\text {in }}\left[(1-D)^{2} L_{2}+\left(D+D^{2}\right) L_{1}\right] \\
b_{0}=2 V_{\text {in }}(1-D)^{4} R_{\mathrm{L}}
\end{array}\right.
$$

and

$$
\left\{\begin{array}{l}
m_{3}=(1-D)^{2} V_{\text {in }} R_{\mathrm{L}} L_{2} C_{1} C_{2} \\
m_{2}=V_{\text {in }}\left[(1-D)^{2} L_{2} C_{1}+L_{2} C_{2}\right] \\
m_{1}=V_{\text {in }}\left[\frac{L_{2}}{R_{\mathrm{L}}}+(1-D)^{4} R_{\mathrm{L}} C_{1}+2 D(1-D)^{2} R_{\mathrm{L}} C_{2}\right] \\
m_{0}=V_{\text {in }}\left[(3 D+1)(1-D)^{2}\right]
\end{array} .\right.
$$

$G_{i l d}(s)$ will affect the current loop transfer function, and $G_{v d}(s)$ will affect the voltage loop transfer function. According to $G_{i l d}(s)$ and $G_{v d}(s)$, the controller should be designed to make the open loop transfer function of the entire system
TABLE IV

SPeCifications of the Main CirCuit

\begin{tabular}{ll}
\hline \hline Parameter & Value \\
\hline Input voltage $V_{\text {in }}$ & $20 \mathrm{~V}$ \\
Output voltage $V_{\mathrm{o}}$ & $70 \mathrm{~V}$ \\
Switching frequency $f$ & $50 \mathrm{kHz}$ \\
Output load $R_{\mathrm{L}}$ & $200 \Omega$ \\
Output power $P_{\mathrm{o}}$ & $24.5 \mathrm{~W}$ \\
Current ripple ratio $L_{1}$ & $<30 \%$ \\
Current ripple ratio $L_{2}$ & $<30 \%$ \\
Voltage ripple ratio $C_{1}$ & $<10 \%$ \\
Voltage ripple ratio $C_{2}$ & $<0.1 \%$ \\
\hline \hline
\end{tabular}

having enough stability margin.

\section{Design Procedure and Simulation Results}

The specifications of the main circuit are shown in Table IV. The duty cycle is designed according to the voltage gain of the converter.

$$
D=1-\frac{1}{\sqrt{M}}=1-\sqrt{\frac{V_{\text {in }}}{V_{\mathrm{o}}}}=0.4655 \text {. }
$$

The inductors and capacitors are designed according to the Table IV and ripple ratios analyzed in Section III. The conditions for the inductance value and capacitance value are deduced as follows:

$$
\begin{gathered}
L_{1}>\frac{(1-D)^{4} R_{\mathrm{L}} T}{0.3} \\
L_{2}>\frac{(2-D)(1-D)^{2} D R_{\mathrm{L}} T}{0.3} \\
C_{1}>\frac{D T}{0.1 R_{\mathrm{L}}(1-D)^{2}} \\
C_{2}>\frac{D T}{0.001 R_{\mathrm{L}}} .
\end{gathered}
$$

Therefore, the parameters of the inductors and capacitors are selected as follows: $L_{1}=3 \mathrm{mH}, L_{2}=3 \mathrm{mH}, C_{1}=10 \mu \mathrm{F}$ and $C_{2}$ $=100 \mu \mathrm{F}$.

To verify theoretical analysis, simulation is done by MATLAB/Simulink. Fig. 5 shows the time-domain simulation waveforms of the inductor currents $i_{L 1}$ and $i_{L 2}$, output voltage $v_{\mathrm{o}}$, driving voltage $v_{\mathrm{G} 1}$ and diode voltage $v_{\mathrm{D} 1}$ for the proposed converter. The simulation waveforms in time-domain show the converter operates in CCM, and the output voltage is about $70 \mathrm{~V}$, which is equal to the theoretical value.

\section{EXPERIMENTAL RESULTS}

The experiment circuit is built to verify the theoretical and 


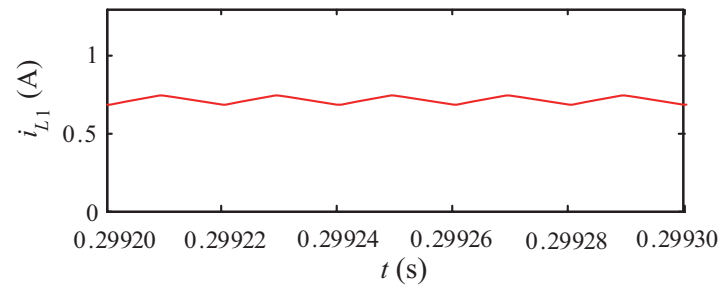

(a)

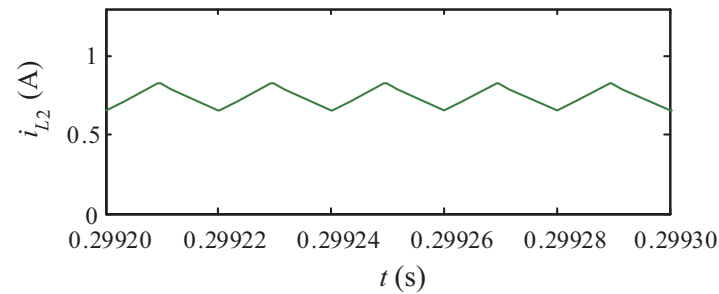

(b)

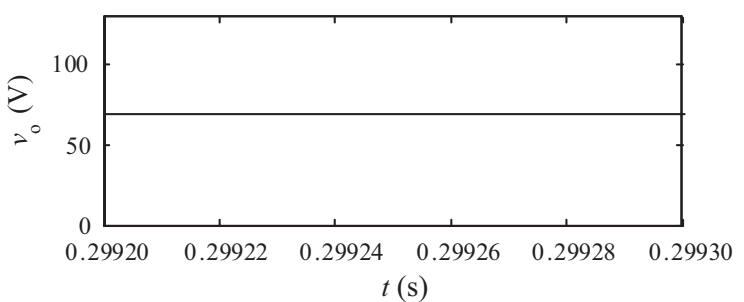

(c)

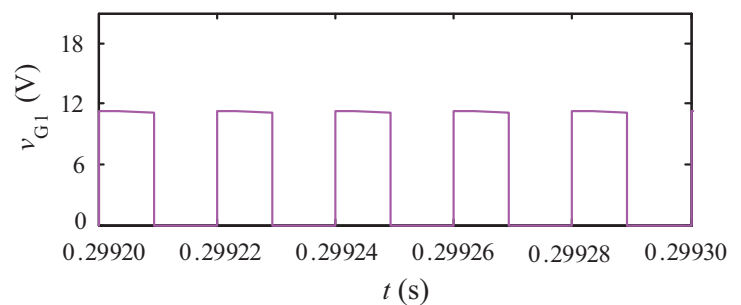

(d)

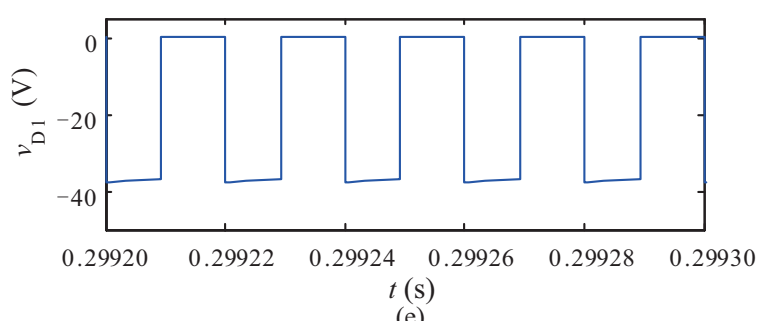

(e)

Fig. 5. Simulated waveforms of the proposed converter.

simulation results. The parameters of the circuit experiment are same as those parameters presented in the simulations of Section VII. IRFP4668 is chosen as the power switch. MBR40250 is selected as the diode.

The average current mode control is applied in the experiment, and the controller is designed according to the transfer functions of $G_{v d}(s)$ and $G_{i l d}(s)$ shown in (23) and (24).

The schematic diagram of average current mode control is shown in Fig. 6(a). The diagram of current loop and voltage loop are given in Fig. 6(b) and (c). The bode plots of $G_{v d}(s)$ and $G_{i l d}(s)$ are shown in Fig. 7(a) and (b), respectively. Fig. 7(c) shows that when applying the average current mode control, the stability margin of the open loop transfer function

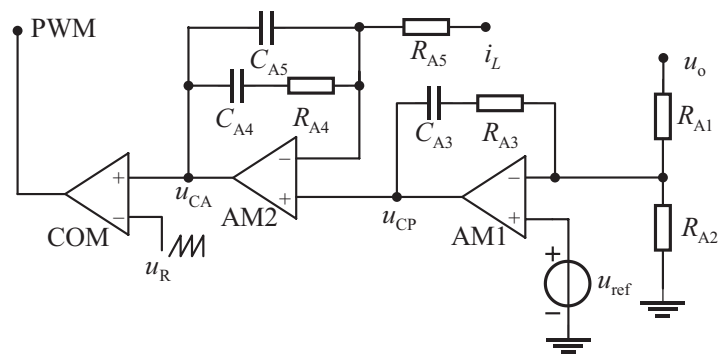

(a)

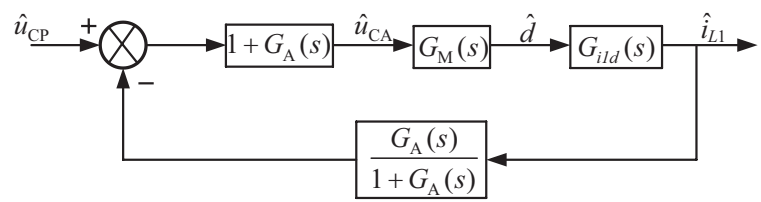

(b)

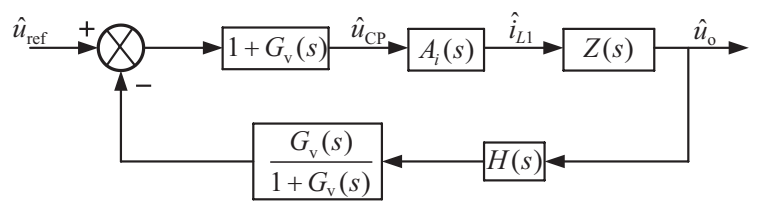

(c)

Fig. 6. Schematic diagram of control method and diagram of current loop and voltage loop. (a) Schematic diagram of average current mode control. (b) Diagram of current loop. (c) Diagram of voltage loop.

of entire system is about $90^{\circ}$.

Fig. 8 shows the time-domain experimental waveforms of the inductor currents $i_{L 1}$ and $i_{L 2}$, input current $i_{\text {in }}$, output voltage $v_{\mathrm{o}}$, driving voltage $v_{\mathrm{G} 1}$ and diode voltage $v_{\mathrm{D} 1}$ for the proposed converter. From Fig. 8(a), the proposed converter operates in CCM, and the input current is non-pulsating. The average input current of $i_{\text {in }}$ is $1.23 \mathrm{~A}$, and the average currents of $i_{L 1}$ and $i_{L 2}$ are $0.66 \mathrm{~A}$ and $0.57 \mathrm{~A}$. According to the average model, the average currents of the inductors should be $0.57 \mathrm{~A}$ and $0.655 \mathrm{~A}$, the average input current should be $1.225 \mathrm{~A}$. The experimental results of the average inductor currents coincide with the average model well. From Fig. 8(b), the output voltage is $70 \mathrm{~V}$, which is in accordance with the average model. Due to the leakage inductance of the inductor and the stray inductance in line, some voltage spikes appear in the waveform of the output voltage.

In order to compare the efficiency of the proposed converter with the converters in [10], [12] and [13], the experiments have been done. The circuit parameters of the above converters have been selected as follows: $L_{1}=3 \mathrm{mH}, L_{2}=3 \mathrm{mH}, C_{1}=10 \mu \mathrm{F}$ and $C_{2}=100 \mu \mathrm{F}$. The input voltage is set to be $20 \mathrm{~V}$, the output voltage is $70 \mathrm{~V}$. The experimental results of the converters with different loads, $R_{\mathrm{L}}=200 \Omega, 300 \Omega, 400 \Omega$, are given in the Table V. Fig. 9 shows the experimental efficiency of the above converters under different loads. Compared with the converter in [10], [12] and [13], efficiency of the proposed converter has been improved due to the reduced inductor currents and the 


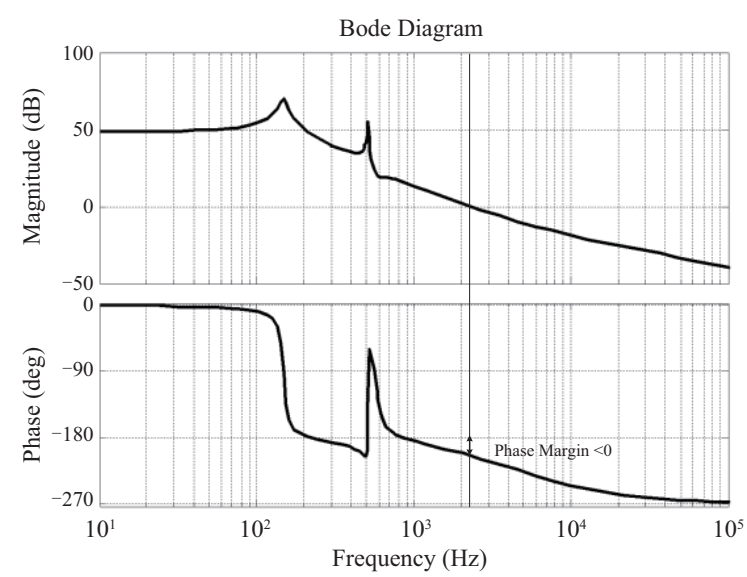

(a)

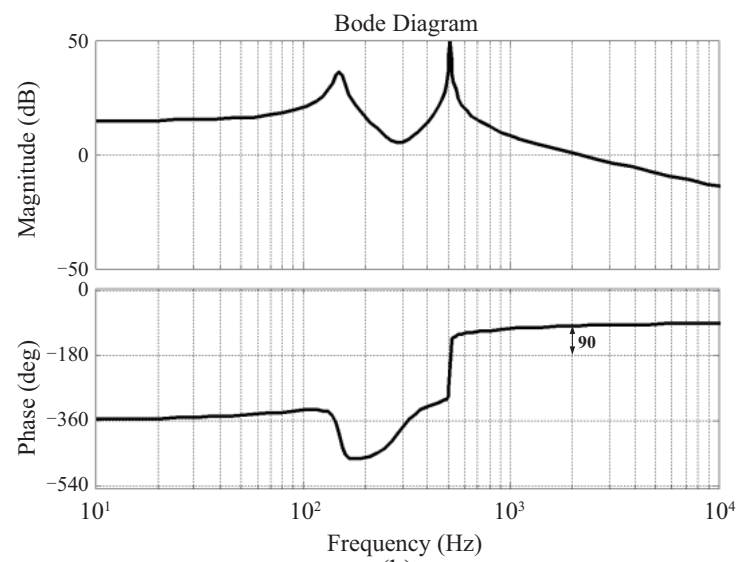

(b)

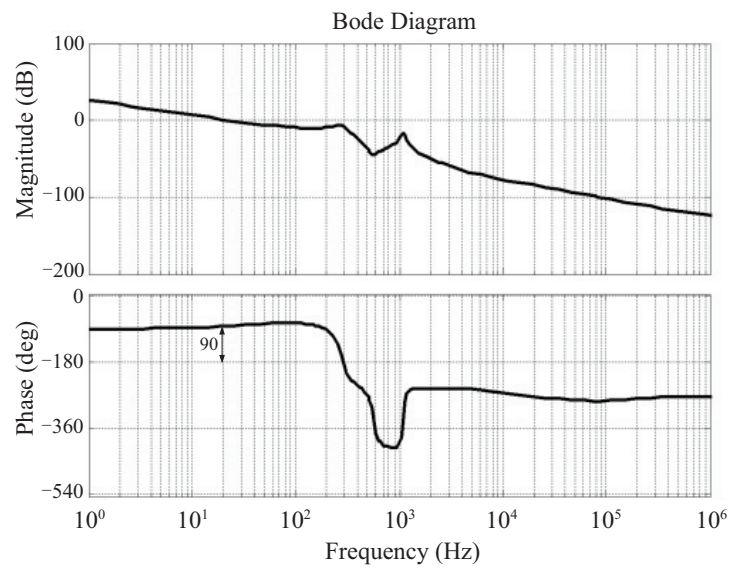

(c)

Fig. 7. Bode diagram. (a) Bode diagram of $G_{v d}(s)$. (b) Bode diagram of $G_{i l d}$ $(s)$. (c) Bode diagram of open loop transfer function of entire system when applying average current mode control.

lower voltage stress on power switch $\mathrm{S}_{1}$.

Fig. 10 is the transient response curves of the output voltage when the load and input voltage are disturbed. In Fig.10(a), switching the load from $500 \Omega$ to $150 \Omega$ at time $t_{1}$, the output voltage suddenly drops and then returns to astable value. Switching the load from $150 \Omega$ to $500 \Omega$ at time $t_{2}$, the output voltage suddenly rises and then returns to $70 \mathrm{~V}$. In Fig. 10(b), switching the input voltage from $20 \mathrm{~V}$ to $25 \mathrm{~V}$ at time $t_{3}$,

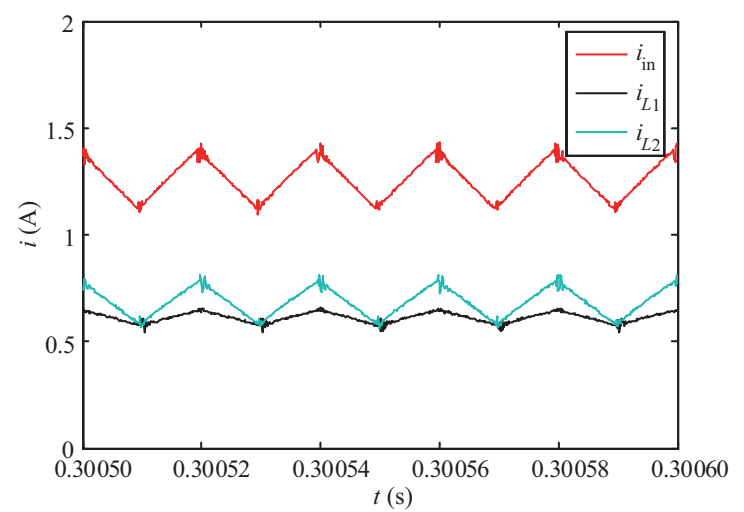

(a)

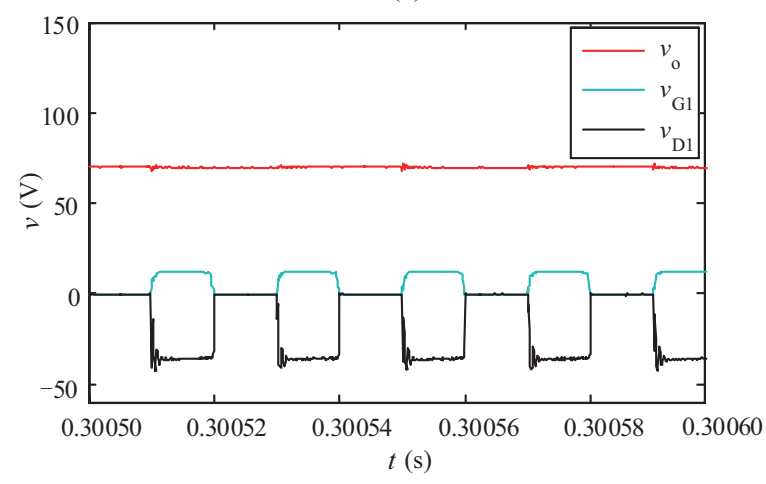

(b)

Fig. 8. Experimental waveforms. (a) Current waveforms. (b) Voltage waveforms.

TABLE V

The Experimental Results of the Converters With Different Loads

\begin{tabular}{lcccc}
\hline & & $R_{\mathrm{L}}=200 \Omega$ & $R_{\mathrm{L}}=300 \Omega$ & $R_{\mathrm{L}}=400 \Omega$ \\
\hline \multirow{2}{*}{$\mathrm{PCV}$} & $I_{\text {in }}$ & $1.46 \mathrm{~A}$ & $0.91 \mathrm{~A}$ & $0.65 \mathrm{~A}$ \\
& $\eta$ & $83.9 \%$ & $89.74 \%$ & $94.23 \%$ \\
$\mathrm{C}[13]$ & $I_{\text {in }}$ & $1.53 \mathrm{~A}$ & $0.92 \mathrm{~A}$ & $0.65 \mathrm{~A}$ \\
& $\eta$ & $78.03 \%$ & $88.76 \%$ & $94.23 \%$ \\
$\mathrm{C}[12]$ & $I_{\text {in }}$ & $1.77 \mathrm{~A}$ & $0.96 \mathrm{~A}$ & $0.68 \mathrm{~A}$ \\
& $\eta$ & $69.21 \%$ & $85.07 \%$ & $90.07 \%$ \\
$\mathrm{C}[10]$ & $I_{\text {in }}$ & $2.12 \mathrm{~A}$ & $1.04 \mathrm{~A}$ & $0.73 \mathrm{~A}$ \\
& $\eta$ & $57.78 \%$ & $78.53 \%$ & $83.90 \%$ \\
\hline \hline
\end{tabular}

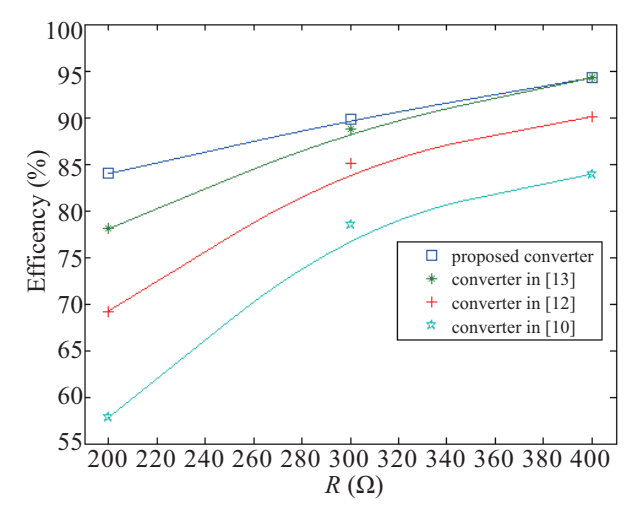

Fig. 9. Experimental efficiency of the proposed converter, the converters in [10], [12] and [13]. 


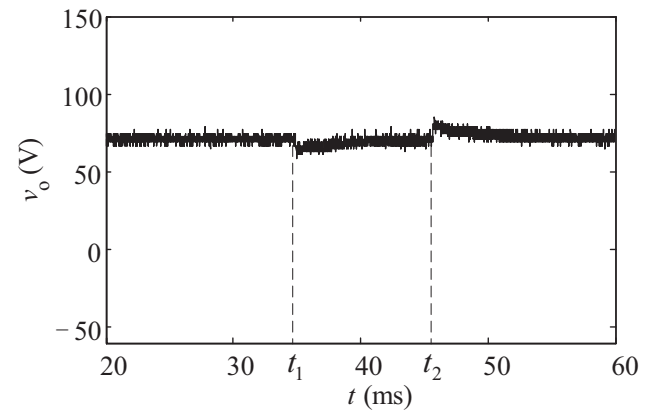

(a)

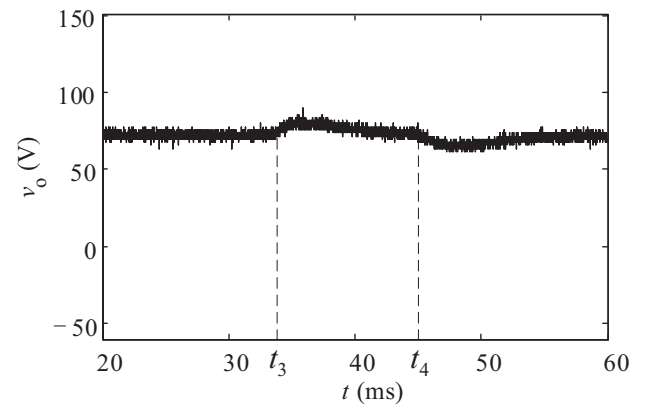

(b)

Fig. 10. Transient response of output voltage. (a) Load disturbance. (b) Input disturbance.

switching the input voltage from $25 \mathrm{~V}$ to $20 \mathrm{~V}$ at time $t_{4}$, the output voltage can stabilize after a short time. The proposed converter has a good dynamic response.

\section{CONCLUSIONS AND Future Work}

A novel quadratic boost converter is presented in this paper. The advantages of the proposed converter are listed as follows: the inductors' average currents are lower than that in [10], [12] and [13], that is helpful for reducing the copper losses of the inductors and increasing the efficiency of the converter; the input current is continuous; the voltage stress on power switch $\mathrm{S}_{1}$ is relatively low. Steady state analysis and small signal model have been discussed under CCM. The average current mode control was applied in the experiment to achieve an output power of $24.5 \mathrm{~W}$. The efficiency of the proposed converter can reach $95 \%$ when the load is $500 \Omega$. In the future work, two power switches will be soft-switched to improve the efficiency of the converter.

\section{REFERENCES}

[1] F. Blaabjerg, F. Iov, T. Kerekes, and R. Teodorescu, "Trends in power electronics and control of renewable energy systems," in Proceedings of 14th International Power Electronics and Motion Control Conference EPE-PEMC 2010, Ohrid, 2010, pp. K-1-K-19.

[2] A. A. Fardoum and E. H. Ismail, "Ultra step-up DC-DC converter with reduced switch stress," in IEEE Transactions on Industry Applications, vol. 46, no. 5, pp. 2025-2034, Sept. 2010.

[3] S. Ben-Yaakov and I. Zeltser, "The dynamics of a PWM boost converter with resistive input," in IEEE Transactions on Industry Applications, vol. 46, no. 3, pp.613-619, 1996.

[4] Q. Zhao, F. Tao, and F. C. Lee, "A front-end DC/DC converter for network server applications," in 2001 IEEE 32nd Annual Power
Electronics Specialists Conference, Vancouver, BC, 2001, pp. 15351539 , vol. 3.

[5] X. Liu, X. Zhang, X. Hu, H. Chen, L. Chen, and Y. Zhang, "Interleaved high step-up converter with coupled inductor and voltage multiplier for renewable energy system," in CPSS Transactions on Power Electronics and Applications, vol. 4, no. 4, pp. 299-309, Dec. 2019.

[6] A. A. A. Freitas, F. L. Tofoli, E. M. S. Júnior, S. Daher, and F. L. M. Antunes, "High-voltage gain DC-DC boost converter with coupled inductors for photovoltaic systems", in IET Power Electronics, vol. 8, no. 10, pp. 1885-1892, 2015.

[7] D. Sivaraj, M. Arounassalame, "High gain quadratic boost switched capacitor converter for photovoltaic applications", in Power Control Signals and Instrumentation Engineering (ICPCSI) 2017 IEEE International Conference, 2017, pp. 1234-1239.

[8] M. Forouzesh, Yam P. Siwakoti, S. A. Gorji, F. Blaabjerg, and B. Lehman, "Step-Up DC-DC Converters: A Comprehensive Review of Voltage- Boosting Techniques Topologies and Applications", in IEEE Transactions on Power Electronics, vol. 32, no. 12, pp. 9143-9178, 2017.

[9] D. S. Wijeratne and G. Moschopoulos, "Quadratic power conversion for power electronics: principles and circuits," in IEEE Transactions on Circuits and Systems I: Regular Papers, vol. 59, no. 2, pp. 426438, Feb. 2012

[10] F. L. Luo and H. Ye, "Positive output cascade boost converters," in IEE Proceedings-Electric Power Applications, vol. 151, no. 5, pp. 590-606, 9 Sept. 2004.

[11] M. G. Ortiz-Lopez, J. Leyva-Ramos, E. E. Carbajal-Gutierrez, and J. A. Morales-Saldana, "Modelling and analysis of switch-mode cascade converters with a single actives witch," in IET Power Electronics, vol. 1, no. 4, pp. 478-487, 2008

[12] Y. M. Ye and K. W. E. Cheng, "Quadratic boost converter with low buffer capacitor stress," in IET Power Electronics, vol. 7, no. 5, pp. 1162-1170, 2014.

[13] F. Wang, "A novel quadratic boost converter with low current and voltage stress on power switch for fuel-cell system applications", in Renewable Energy, vol. 115, pp. 836-845, 2017.

[14] G. Li, X. Jin, X. Chen and X. Mu, "Analysis and Circuit Implementation of a Novel Quadratic Boost Converter with Low Inductor Current,"in 2019 IEEE 10th International Symposium on Power Electronics for Distributed Generation Systems (PEDG), Xi'an, China, 2019, pp. 542-546.

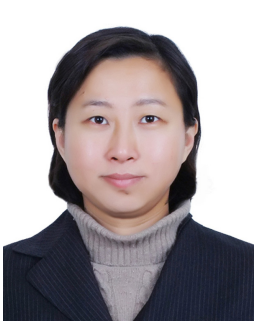

Guanlin Li received the B.S., M.S., and Ph.D. degrees from Harbin Institute of Technology, Harbin, China, in 2002, 2004, and 2008, respectively. Dr. $\mathrm{Li}$ is currently an Associate Professor in the School of Electrical Engineering, Dalian University of Technology, Dalian, China. Her research interests include power converters, wireless power transmission, fractional circuit and nonlinear circuit.

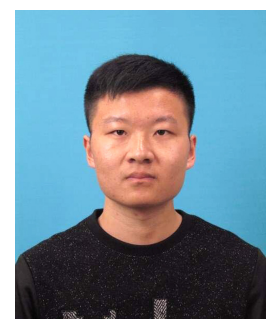

Xin Jin was born in Jingmen, Hubei province, China. He received his B.S. degree in electrical engineering and automation from Shandong Technology and Business University, China, in 2017. He is currently studying for his master's degree in electrical engineering at Dalian University of Technology. His current research interests include modeling and control of power converters, soft switching and power electronics applications in renewable energy. 


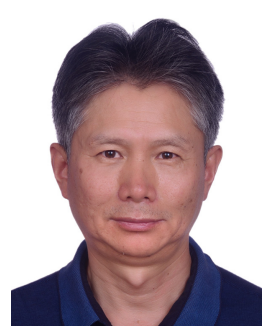

Xiyou Chen was born in 1962, he received the B.Sc., M.Sc. and Ph.D. degrees from Harbin Institute of Technology, Harbin, China, in 1982, 1985, and 2000, respectively. Now, He works as a Professor in the School of Electrical Engineering, Dalian University of Technology, Dalian, China. He is a member of Chinese Society of Electrical Engineering (SCEE). Currently his research interests are in the areas of wireless power transmission, green power conversion, power filter. As a Liaoning Province prestigious teacher, he is also good at the course teaching including the fundamentals of electric circuits and electric network analysis.

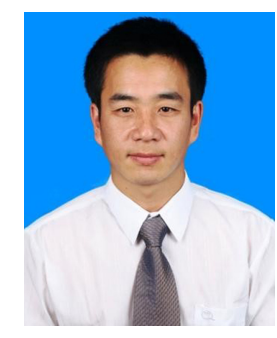

Xianmin Mu was born in Heilongjiang Province, China, in 1973. He received the M.Sc. degree in 2002 and $\mathrm{Ph} . \mathrm{D}$. degree in 2007 from Harbin Instituted of Technology. Since 2013, he was an Associate Professor in School of Electrical Engineering, Dalian University of Technology. Now he's interested in wireless power transmission, power filter, and power electronic converter. 